управления инфлляционными процессами в силу разностороннего характера воздействия на уровень цен, что поможет экономике в целом находиться в стабильном положении.

1 Сущность "цифровой инсрляции" [Электронный ресурc] URL: http://digitaleconomy.ru/mneniya/inflyatsiya-inflyatsii-v-usloviyakh-perekhoda-v-tsifrovuyu-formatsiyu

2 А.М. Лопухов Определение инфрляции // Словарь терминов и понятий по обществознанию. 9-е изд. 2016. 512 c.

3 Формула количественной теории денег [Электронный ресурc] URL: http://www.grandars.ru/student/finansy/kolichestvennaya-teoriya-deneg.html

${ }_{4}^{4}$ Функционирование блокчейна [Электронный ресурc] URL: http://bestinvestpro.com/blokchejnchto-eto-ponyatnym-yazykom/

5 Сущность эфффекта Amazon [Электронный ресурс] URL: https://www.entrepreneur.com/ article/325556

6 "Цифровая инфляция" в США [Электронный ресурc] URL: https://econs.online/articles/ekonomika/tsifrovaya-inflyatsiya/

\title{
DIGITAL INFLATION AS A RESULT OF THE DEVELOPMENT OF DIGITAL ECONOMY
}

\author{
(C) 2020 Timofeeva Arina Yuryevna \\ Student \\ Samara State University of Economics \\ E-mail: arina_tim007@mail.ru
}

Keywords: digital inflation, Fisher's equation, digital technology, anti-inflation effect, e-commerce.

Now economics is developing, therefore end-to-end technologies are appeared. They participate in almost all areas of the economic industry and wield influence on prices. This article is about digital inflation. It is phenomenon in modern economy.

УДК 330.12

Код РИНЦ 06.00.00

\section{ОСОБЕННОСТИ ОРГАНИЗАЦИИ ЛОГИСТИЧЕСКОЙ СИСТЕМЫ СБЫТА ТОРГОВЫХ ПРЕДПРИЯТИЙ}

\author{
(ㄷ 2020 Тойменцева Ирина Анатольевна \\ доктор экономических наук, доцент \\ Самарский государственный экономический университет \\ E-mail: tia67@rambler.ru
}

Ключевые слова: сбытовая деятельность, оптовая и розничная торговля, ассортимент, конкурентоспособность, реклама, транспортировка, логистические посредники. 
В статье изучена сущность сбытовой деятельности предприятий оптовой торговли, рассмотрено содержание сбытовой деятельности в зависимости от формы оптовой торговли, а также исследованы механизмы управления сбытовой деятельностью предприятия оптовой торговли. Авторы отмечают, что сбытовая деятельность оптовых предприятий заключается не только в сбыте продукции, но и в ее хранении, транспортировке и грузопереработке, поэтому в целом она направлена на повышение конкурентоспособности предприятия, удовлетворение потребностей клиентов и увеличение прибыли.

Торговля, в том числе и оптовая, играют существенную роль в формировании товарного ассортимента для розничной торговли, а также способствует продвижению продукции по каналам сбыта от производителя к конечным потребителям.

Хорошо слаженная работа оптового предприятия способствует формированию широкого ассортимента розничных предприятий, обеспечивая, в том числе бесперебойность поставок в нужное место, в строго определенном объеме и с минимальными издержками.

Согласно проведенным исследованиям, выявлено, что сбытовые функции по сравнению с производителями продукции и предоставления услуг лучше выполняют именно оптовые организации, потому что располагают большими складскими площадями, осуществляют разукрупнение партий товаров, поступающих от производителей и комплектацию широкого ассортимента товаров для розничных торговых сетей‥ Также оптовые компании часто оказывают дополнительные услуги широкого спектра, такие как доставка, страхование, экспедирование грузов и др.

На пути следования грузов от оптовой компании до конечных покупателей могут быть оказаны такие услуги как:

- Реклама на местах продаж;

- Проведение мероприятий по увеличению продаж;

- Доставка товаров;

- Предпродажная подготовка;

- Организация сервисных центров, при поддержке производителей, для технически сложных товаров.

Логистическая концепция сбыта исходит из общей концепции оптового предприятия и содержит основные аспекты сбытовой политики с целью повышения его конкурентоспособности².

Управление оптовыми запасами состоит из нормирования и мониторинга его состояния. Формирование товарно-материальных запасов происходит в первую очередь в зависимости от спроса на товары и услуги. Управление запасами на каждом уровне может способствовать бесперебойной поставке продукции оптовым потребителям, ускоряя оборот и минимизируя стоимость хранения.

Управление ассортиментом продукции включает в себя формирование ассортимента для оптовых и розничных предприятий, учет имеющегося на складе товара и своевременное его обновление, согласно изменяющимся предпочтениям конечных потребителей.

Помимо управления оптовыми запасами и ассортиментом продукции, при рассмотрении оптовой торговли следует учитывать и другие особенности сбытовой деятельно280 
сти, к которым можно отнести точное определение целевого рынка, формирование долгосрочных и перспективных отношений с заказчиками.

Также планирование сбытовой деятельности зависит от формы оптовой торговли. В результате каждой форме оптовой торговли соответствует перечень направлений коммерческой деятельности, которые представлены в таблице.

На сегодняшний момент наибольшее распространение получили такие формы организации коммерческой деятельности оптовых предприятий как:

- Мелкооптовые торговые организации, представленные оптовыми базами и складами;

- Крупнооптовые торговые организации, имеют крупные распределительные центры, обладают обширной клиентской базой, из которых часть клиентов могут забирать заказанные товары сами, а другая часть оформляют доставку товара;

- Оптовые посредники обеспечивают закупку товара у производителей внутри страны или у иностранных производителей и далее поставляют товар в мелкооптовые компании или продают товар через биржи, а также через механизмы государственных закупок.

Формы организации коммерческой деятельности в оптовой торговле

\begin{tabular}{|c|c|}
\hline Форма оптовой торговли & Содержание коммерческой деятельности \\
\hline $\begin{array}{l}\text { Оптово-посредническое } \\
\text { предприятие }\end{array}$ & $\begin{array}{l}\text { Предприятия данной формы функционируют по товарному призна- } \\
\text { ку, специализируются на обеспечении потребителей определен- } \\
\text { ным видом продукции }\end{array}$ \\
\hline Оптовые торговые центры & $\begin{array}{l}\text { В оптовых торговых центрах обычно есть выставочный зал с пред- } \\
\text { ставленными образцами товаров. Оптовая и розничная торговля } \\
\text { связаны с этой формой организации бизнеса }\end{array}$ \\
\hline Оптовые склады & $\begin{array}{l}\text { Главное условие существования предприятий данной формы - это } \\
\text { наличие большого объема товарооборота. Особенность этого } \\
\text { модуля в том, что выставочный зал и офис географически удалены } \\
\text { от складских помещений }\end{array}$ \\
\hline Оптовые рынки & $\begin{array}{l}\text { Продажа товаров на оптовых рынках регулируется гражданским } \\
\text { законодательством, основанным на равенстве участников эконо- } \\
\text { мических отношений, неприкосновенности их собственности и } \\
\text { недопустимости вмешательства администрации рынка в их ком- } \\
\text { мерческую деятельность }\end{array}$ \\
\hline
\end{tabular}

Опираясь на данные формы организации, оптовые компании решают вопрос об организации единого централизованного склада или системы складов, при этом допустимо их совместное взаимодействие. Основополагающим фактором для этого служит соотношение издержек на содержание складов и улучшения качества обслуживания клиентов оптовика.

Если сравнивать работу и общее состояние складов и распределительных центов в России и Европе, то можно сделать ряд заключений. Превосходство складов Европы над Россией заключается в том, что у них выше автоматизация, а соответственно все процессы происходят значительно быстрее. Высокая автоматизация складов в Европе яв- 
ление в какой-то степени вынужденное. В первую очередь, потому что компаниям не хватает персонала для работы на складах. Население Европы стремительно стареет. А на обычном складе сотрудник перемещается по маршруту, заданной системой управления складом. За рабочую смену сотруднику потребуется пройти несколько километров, чтобы скомплектовать товар. Это требует от сотрудника определенной фиизческой формы. При автоматизации склада можно реализовать подбор товара, таким образом, чтобы сотрудник стоял на месте, а товар сам к нему перемещался. Когда сотрудник набирает нужное количество единиц товара, лишний товар по транспортеру возвращается на место. При автоматизации работы склада не требуется высокая степень физической выносливости, поэтому на такой работе может работать человек пенсионного возраста.

При автоматизации склада сокращается количество работников, что снижает расходы на зарплату персонала. В странах, где недешевая рабочая сила и наличие ее дефицита, компании просто вынуждены искать различные варианты снижения затрат. В России также намечается тенденция увеличения среднего возраста работающих.

В Европе власти стараются создавать комфортные условия для размещения складов на собственных территориях предприятия или организовывают строительство целой складской системы, включающей склады от разных производителей за пределами города. В Германии, например для организации собственного производства, в том числе и строительства склада, выделяют дотацию, равную половине стоимости инвестиций. В нашей стране у производителей нет таких возможностей. В настоящее время из собственников складов, сдаваемых в аренду мало тех, кто вкладывается в автоматизацию склада. Собственники нацелены на получение максимальной прибыли в ближайшее время, а следует мыслить стратегически и видеть перспективу долгосрочных вложений.

Важным элементом стимулирования сбыта в системе оптовой торговли являются маркетинговые исследования рынка, которые осуществляются этапами:

- изучения микроэкономических параметров рынка и аспектов его состояния;

- анализ распределения рыночных долей между компаниями-конкурентами и оценки развития оптовой организации;

- изучения новых товаров и услуг;

- изучения оптовых покупателей и тенденций их поведения на рынке, оценки их возможностей;

- изучения ценовой политики;

- анализ методов сбыта и существующих каналов распределения;

- изучения способов стимулирования сбыта.

Проанализировав состояние рынка, следуя этапам, приведенным выше, оптовики выбирают оптимальные методы и механизмы развития сбытовой деятельности, и увеличение потребителей. Для этого используют следующие формы продвижения товаров и услуг на рынок:

- планирование, организация и проведение рекламных мероприятий;

- организация торговых выставок и ярмарок;

- установление персональных контактов и продаж розничным торговцам;

- предоставление дополнительных услуг покупателям и персональных скидок. 
Успех сбытовой логистики во многом зависит от того, насколько качественно и эфрфективно происходит процесс управления сбытом и координации маркетинговых каналов распределения на предприятии оптовой торговли. На первом этапе проводится поиск посредников и установление с ними договорных отношений, которыми определяется оптимальный размер товарных заказов и условия приемки, хранения, сортировки и отправки товаров покупателям. Заключительным этапом является контроль исполнения договорных обязательств всех участников.

Сегодня конкуренция на рынке между фирмами достаточно велика в связи, с чем возрастает риск коммерческой деятельности предприятий оптовой и розничной торговли. О высоком динамизме уровня влияния предпринимательских рисков во многих отраслях народного хозяйства, в том числе в сфере услуг и логистике, отмечают в своей статье отечественные ученые-экономисты ${ }^{3}$.

Производитель продукции должен задумываться не только о качестве своего товара, но и о том, как доставить его до потребителя. За это отвечает распределительная логистика. Она выступает связующим звеном между производителем и покупателем, реагирует на возникший спрос и старается своевременно удовлетворить его в нужном количестве и с минимальными затратами.

Осуществлять сбыть своей продукции фирма-производитель может как своими силами (инсорсинг), так и за счет логистических посредников (аутсорсинг).

Аутсорсингом является передача частично или полностью каких-либо функций или бизнес-процессов, которые предприятие не может выполнить сама или точно знает, что эти функции лучше выполнят специализированные сторонние компании, причем с минимальными издержками 4 . Такие организации называют посредниками или провайдерами логистических услуг.

Посредником может выступать как фризическое, так и юридическое лицо, цель которого заключается в продвижении товара до конечного потребителя. К логистическим посредникам относят специализированные транспортно-экспедиторские организации, грузоперерабатывающие предприятия, стивидорные компании, терминалы, склады, распределительные центры и другие организации.

Каждая из посреднических фирм предоставляет различный перечень услуг и выполняет определенный спектр функций, в зависимости от своей специализации.

Вспомогательными логистическими посредниками чаще всего выступают учреждения финансового и информационного сервиса, страховые и охранные компании, таможенные брокеры, учреждения лицензирования, стандартизации, сертификации и другие.

Предприятия, которые используют в своей деятельности логистических посредников, могут получить от взаимодействия с ними определенные выгоды:

- увеличивается скорость реализации товаров, снижаются запасы на складе, что способствует увеличению оборачиваемости капитала предприятия и повышению его дохода.

Повышается возможность более оперативно и своевременно реагировать на изменение рыночной конъюнктуры за счет приближенности продавца к покупателю.

Появляется возможность повысить конкурентоспособность товаров благодаря сокращению сроков поставки товаров. 
Появляется обратная связь между производителем и потребителем.

При выборе посредников стоит учитывать следующие критерии: правовая обеспеченность, уверенность в качестве предоставляемых услуг, надежность, устойчивость финансового положения и его репутация.

Важнейшее место среди логистических посредников занимают те, кто осуществляет функции физического распределения и поддерживающие функции.

На сегодняшний момент, благодаря бурному развитию мирового бизнеса, число логистических провайдеров значительно выросло. Согласно Западной классификации логистической деятельности, можно выделить 5 уровней логистического сервиса (Party Logistics - PL), отличия которых в спектре оказываемых услуг и технологическом уровне 5 .

1PL (First Party Logistics) - Автономная логистика, на основе инсорсинга. Данный сервис характеризуется тем, что сам владелец товара, то есть производитель осуществляет выполнение всех логистических функций.

2PL (Second Party Logistics) - Традиционная логистика или "логистика второй стороны". Заключается в частичном аутсорсинге, то есть фирма-производитель берет на себя часть функций, а другую часть передает сторонней транспортной организации.

3PL (Third Party Logistics) - Комплексный логистический аутсорсинг. Данный тип сервиса предполагает передачу всех или наиболее основных логистических функций оператору логистических услуг. Оператор оказывает комплекс услуг, среди которых может быть транспортировка, складирование и экспедирование груза.

4PL (Fourth Party Logistics) - Интегрированный логистический аутсорсинг. Особенность этого сервиса заключается в применении системного подхода к управлению всеми логистическими бизнес-процессами заказчика, планировании и проектировании цепочек поставок, координации действий компании и ее ключевых контрагентов в цепи поставок и их эфффективного взаимодействия.

5PL (Fifth Party Logistics) - "Виртуальная" логистика. 4PL провайдер превращается в $5 \mathrm{PL}$, когда начинает оказывать услуги сетевого бизнеса. Он начинает широко использовать Интернет пространство для оказания всего спектра услуг. Это позволяет осуществлять своевременное, всесторонне и более глубокое взаимодействие с клиентами в режиме реального времени.

В мире насчитывается не так много провайдеров 4 уровня (4 PL), а в России не многочислен и 3 уровень (3 PL). Логистический аутсорсинг в России развивается с ощутимым отставанием от зарубежных стран. В настоящий момент на рынке логистических услуг в России доминируют узкоспециализированные логистические посредники (2 PL), однако все идет к тому, что постепенно фирмы стараются внедрять в свою деятельность я услуги $3 \mathrm{PL}$ провайдеров.

Логистические провайдеры развиваются и совершенствуют предлагаемые сервисы, фирмы стремятся улучшить спектр предоставляемых услуг. Посредники образуют четкие связи между фирмой-производителем и потребителем, понижая издержки по продвижению продукта, создавая тем самым более низкие цены для потребителей.

В результате можно сделать вывод о том, что рациональная организация процессов сбыта (доставка товаров в определенных объемах и в установленные сроки от производителя до конечных потребителей) как в оптовой, так и в розничной торговле имеет 
важное значение для экономии страны в целом. Оптовые компании взаимодействия с розничными сетями становятся наиболее осведомленными об изменяющихся потребностях конечных покупателей, поэтому могут организовать качественную и высокоэффрективную систему сбыта для розничной торговли как самостоятельно, так и при поддержке производителей продукции. играют ведущую роль Строительство автоматизированных складов, распределительных центов и организация совместной деятельности с логистическими компаниями - посредниками способствует увеличению прибыли всех участников логистической цепи.

1 Лесникова, Э.П. Особенности коммерческой и инновационной деятельности в оптовой торговле // Научный журнал НИУ ИТМО. Серия "Экономика и экологический менеджмент". - 2018. №1.

2 Тойменцева И.А., Тойменцева А.А. Логистика как инструмент обеспечения конкурентоспособности предприятий оптовой торговли // Экономика и предпринимательство. 2018. № 12 (101). C. $711-715$.

3 Павлова А.В., Ашмарина С.И. К вопросу об актуальных, нарастающих и ниспадающих рисках предпринимательской деятельности// Вестник Самарского государственного экономического университета. 2019 №12 (182). ${ }^{3}$ Бондаренко В.А, Гузенко Н.В.

${ }_{4}^{4}$ Аутсорсинг логистических услуг: реалии и тенденции // Финансовые исследования №3 (48) 2015. C 176-181.

${ }^{5}$ Мамаев, Э.А. Логистические провайдеры в транспортных системах / Э.А. Мамаев, Е.А. Чеботарева, Н.А. Ковалева // ФГБОУ ВО РГУПС. - Ростов н/Д, 2017 - 130 с.: ил., прил. с. 118-123.

\title{
FEATURES OF ORGANIZATION OF LOGISTICS SYSTEM OF SALES OF TRADING ENTERPRISES
}

\author{
(C) 2020 Toymentseva Irina Anatolyevna \\ Doctor of Economics, Associate Professor \\ Samara State University of Economics \\ E-mail: tia67@rambler.ru
}

Keywords: sales activities, wholesale and retail trade, assortment, competitiveness, advertising, transportation, logistics intermediaries.

The article examined the essence of the marketing activities of wholesalers, reviewed the content of marketing activities depending on the form of wholesale, and explored the mechanisms for managing the marketing activities of wholesalers. The authors note that the marketing activity of wholesale enterprises is not only in the marketing of products, but also in their storage, transportation and cargo handling, therefore, in general, it is aimed at increasing the competitiveness of the enterprise, meeting customer needs and increasing profits. 